\title{
Intracranial Dural Arteriovenous Fistulae with Pial Venous Drainage: Combined Endovascular - Neurosurgical Therapy
}

\author{
David M. Pelz, Stephen P. Lownie, Allan J. Fox and Dominic Rosso
}

\begin{abstract}
Background: Intracranial dural arteriovenous fistula with pial venous drainage may present with hemorrhage or focal neurologic deficit and may be difficult to treat. We wish to summarize the therapeutic approaches to these potentially dangerous lesions and to demonstrate how endovascular and neurosurgical therapies may have complimentary roles in their management. Methods: The clinical and radiological records of all patients who presented to our institution with intracranial dural arteriovenous fistula over the last 5 years were reviewed. In those cases demonstrating pial venous drainage, details of presentation, imaging features, endovascular and surgical therapy and outcome were analyzed. Results: We identified 13 patients with these lesions, 7 of whom presented with intracranial hemorrhage. Six patients were treated with embolization alone. Angiographic cure was achieved in 4 . There was one complication in this group, a subarachnoid hemorrhage following glue injection. Four patients were treated with embolization followed by surgical occlusion of the pial venous drainage. Angiographic cure was achieved in all 4. There was one complication in this group, a facial nerve palsy following glue injection. Three patients were treated by surgery alone, with no complications and complete cure in all. Conclusion: Endovascular therapy of intracranial dural arteriovenous fistula may be curative but is often complex and carries definite risks. Neurosurgical ligation of pial draining veins, with pre-operative embolization when safe, may be a relatively more controlled method to achieve complete cure.
\end{abstract}

\begin{abstract}
RÉSUMÉ: Fistule artérioveineuse durale intracrânienne avec drainage veineux à la pie-mère: traitement endovasculaire et neurochirurgical combiné. Introduction: Les fistules artérioveineuses durales intracrâniennes (FAVs) avec drainage à la pie-mère (DVP) peuvent avoir un tableau initial d'hémorragie ou de déficit neurologique focal et peuvent être difficiles à traiter. Nous faisons un sommaire des approches thérapeutiques de ces lésions potentiellement dangereuses et nous démontrons comment les approches endovasculaires et neurochirurgicales peuvent avoir des rôles complémentaires dans leur traitement. Méthodes: Les dossiers cliniques et radiologiques de tous les patients qui ont été évalués dans notre institution pour une FAV durale intracrânienne au cours des 5 dernières années ont été révisés. Dans les cas chez lesquels il y a eu un drainage de la pie-mère, les détails au moment de l'évaluation initiale, l'imagerie, le traitement endovasculaire et chirurgical et les résultats du traitement ont été analysés. Résultats: Nous avons identifié 13 patients présentant ces lésions, dont 7 qui se sont présentés avec une hémorragie intracrânienne. Six patients ont été traités par embolisation seulement. Une guérison angiographique a été obtenue chez 4. Il y a eu une complication dans ce groupe, soit une hémorragie sous-arachnoïdienne suite à l'injection de colle. Quatre patients ont été traités par embolisation suivie par une occlusion chirurgicale du drainage veineux à la pie-mère. La guérison angiographique a été obtenue chez ces 4 patients. Il y a eu une complication dans ce groupe, une paralysie du nerf facial suite à l'injection de colle. Trois patients ont été traités par la chirurgie seulement, sans complication, et tous ont eu une guérison complète. Conclusion: Le traitement endovasculaire des FAVs durales intracrâniennes peut être curatif, mais il est souvent complexe et comporte des risques. La ligature neurochirurgicale des veines de drainage à la pie-mère, avec embolisation préopératoire quand cette approche est sécuritaire, peut être une méthode relativement plus contrôlée pour obtenir une guérison complète.
\end{abstract}

Can. J. Neurol. Sci. 1997; 24: 210-218

Intracranial dural arteriovenous fistulae (DAVFs) are relatively uncommon vascular malformations which may be asymptomatic or may present with a variety of clinical sequelae, depending on location, arterial supply and venous drainage. ${ }^{1-3}$ Various classifications of these lesions have been proposed, most being based on the pattern of venous drainage. ${ }^{4-6}$ Treatment of the more benign variety (i.e., those with antegrade flow in venous sinuses and no filling of pial subarachnoid veins)

From the Departments of Diagnostic Radiology and Clinical Neurological Sciences, University Campus, London Health Sciences Centre, The University of Western Ontario, London.

RECEIVED NOVEMBER 1, 1996. ACCEPTED IN FINAL FORM APRIL 4, 1997.

Reprint requests to: David M. Pelz, Radiology Department, University Hospital, 339

Windermere Road, Box 5339, London, Ontario, Canada N6A 5A5 
is usually elective and is indicated when symptoms such as a bruit become intolerable. Endovascular therapy may be curative in a large proportion of cases. ${ }^{7.8}$ The more aggressive lesions, which demonstrate pial venous drainage (PVD; also called cortical or leptomeningeal venous drainage) often present with hemorrhage or progressive neurologic deficit due to venous hypertension, and urgent treatment is mandatory. Endovascular therapy may be curative in these patients however it is often difficult to eliminate all of the arterial input and pial venous drainage by embolization alone. Surgical obliteration of the PVD without resection of the dural sinus may in some circumstances be curative. ${ }^{9,10}$ We present our experience over the last 5 years (1991-1996) with these challenging lesions to show the complimentary roles of endovascular and neurosurgical therapy.

\section{Materials AND Methods}

The clinical and radiologic records of all patients who presented to our institution with intracranial DAVFs over the last 5 years were reviewed. In those patients in whom PVD could be definitely identified, details of clinical presentation, imaging features, endovascular and surgical therapy, and outcome were analyzed.

The angiographic protocol both pre- and post-treatment included selective internal and external carotid injections, and subselective catheterizations (i.e., occipital artery, meningohypophyseal trunk) when necessary. In those patients who showed angiographic occlusion of the DAVF on the post-treatment study, further follow-up angiography was generally not performed. In those patients with incomplete occlusion, follow-up studies were performed at 6 month to one year intervals.

\section{RESULTS}

Results are summarized in Table 1 . There were 27 patients identified who presented with symptomatic DAVFs. Of these patients, 13 demonstrated angiographic evidence for PVD. Six patients presented with intracranial hemorrhage, 1 with seizures, 1 with headaches and cerebellar signs, 1 with headaches and a visual field deficit, 2 with tinnitus, 1 with vertigo, and 1 with left hemispheric transient ischemic attacks (TIAs) in whom investigations showed an incidental DAVF. Five lesions involved the transverse and sigmoid sinuses, 2 involved the tentorium, 3 involved the floor of the anterior cranial fossa, and 1 each involved the cavernous sinus, the superior sagittal sinus and the foramen magnum.

Treatment options were discussed with the referring clinicians in all cases. In those cases in which angiography had shown accessible arterial feeders, transarterial embolization was usually the initial therapy of choice. This was then followed by transvenous embolization or a direct surgical approach when feasible. In those cases in which transarterial access was limited or the venous drainage was inaccessible, direct surgical ligation of the PVD was performed.

Six patients were treated with embolization alone, using varying amounts of polyvinyl alcohol particles (PVA), n-butyl cyanoacrylate glue (NBCA) and platinum coils. An angiographic cure was achieved in 4 of these patients. In those patients with an incomplete angiographic cure, the PVD was eliminated and clinical symptoms were significantly improved. There was 1 complication in this group of 6 patients, a subarachnoid hemorrhage following injection of glue into a muscular feeding branch of the vertebral artery (patient CP). This likely occurred due to passage of glue through the nidus of the DAVF into the pial veins, with acute venous hypertension leading to hemorrhage.

Four patients were treated with embolization followed by surgical ligation of the PVD without sinus resection. An angiographic cure was achieved in all of these patients. There was 1

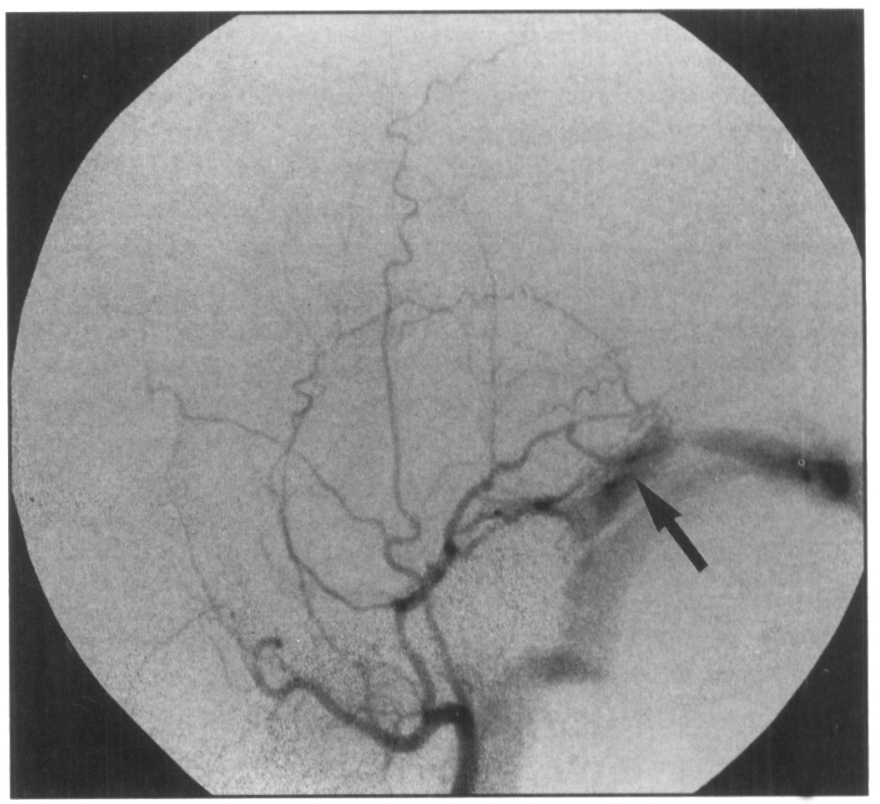

Figure 1: Left internal maxillary arteriograms, lateral view shows the $D A V F$ with early filling of the transverse sinus (arrows).

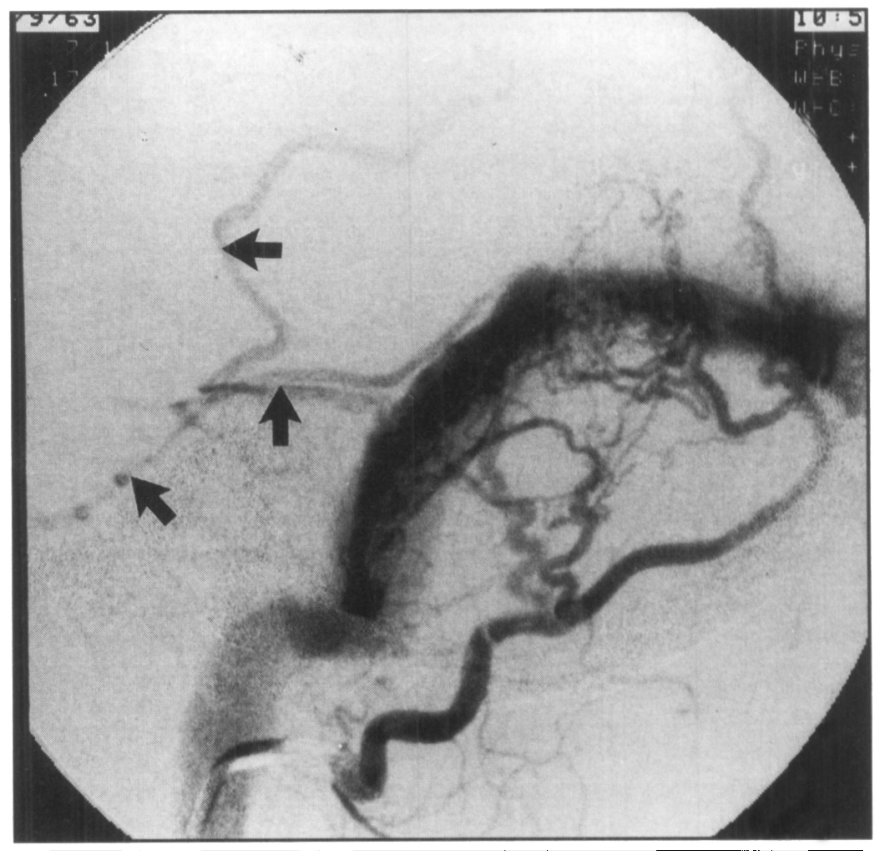

Figure 2: Left occipital arteriograms, lateral view, again shows the DAVF with filling of pial cerebellar veins (arrows). 

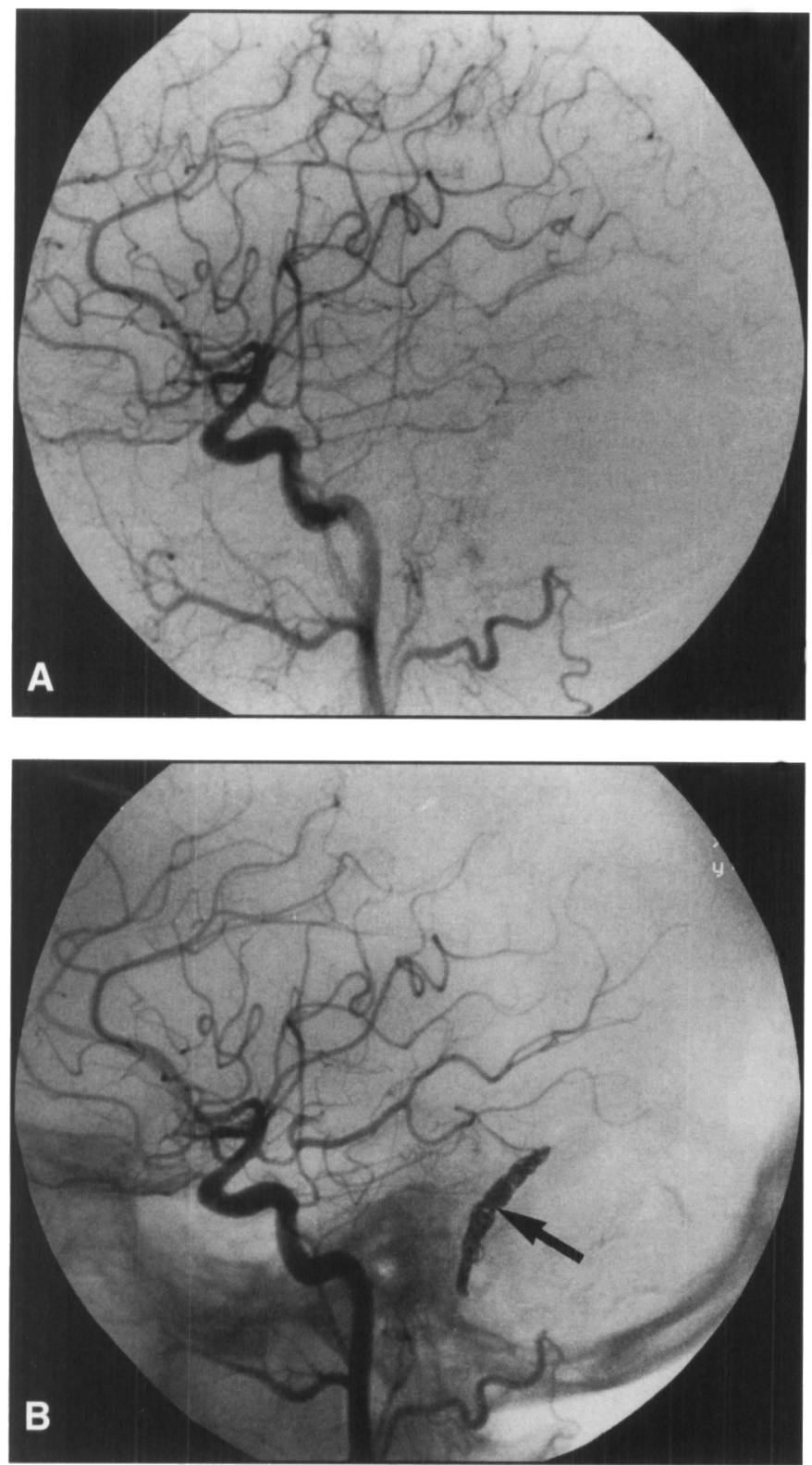

Figure 3: The post-embolization left common carotid arteriogram (lateral views) show's complete occlusion of the lesion. Note coils on the unsubtracted view (arrow, B).

complication in this group, a facial nerve palsy following glue injection into a middle meningeal feeding branch prior to surgery. This likely occurred due to inadvertent embolization of the small petrosal branch supplying the facial nerve. Three patients were treated by surgery alone and a complete angiographic cure was achieved in all of these patients with no complications.

\section{Representative Cases}

\section{1) Patient $L P$}

This 33-year-old woman presented with pulsatile tinnitus. Cerebral angiography showed a DAVF of the left transverse sinus (Figures 1,2 ). Arterial supply was from the left occipital and middle meningeal branches of the left external carotid artery, and meningohypophyseal branches of the left internal carotid artery. There was occlusion of the proximal left sigmoid sinus, with evidence for PVD into left cerebellar

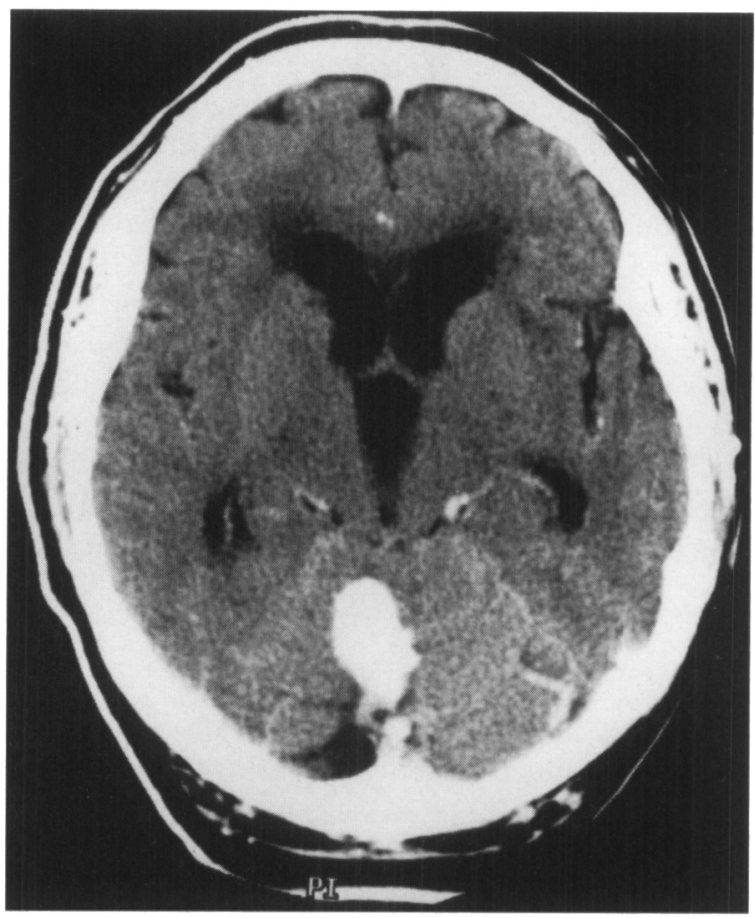

Figure 4: A contrast enhanced CT scan shows a large midline venous varix in the posterior fossa.

and occipital veins. The lesion was initially treated by transarterial embolization of the external carotid artery feeders with NBCA and PVA particles. A transvenous approach was then used to pack the transverse sinus with platinum coils. This resulted in complete occlusion of the lesion (Figure 3).

\section{2) Patient ND}

This 68-year-old male presented with a 4 year history of occipital headaches, dizziness and intermittent visual disturbance. He also experienced difficulty with balance which had progressed over 2-3 months. A CT scan showed a large varix in the midline of the posterior fossa (Figure 4) and angiography confirmed the presence of a DAVF, supplied by both occipital arteries and meningeal branches of both vertebral arteries (Figure 5). Venous drainage was into the large midline venous varix and pial cerebellar veins. Embolization was undertaken to halt his progressive neurologic deficit and to prevent future hemorrhage. Both occipital arteries were embolized with NBCA, resulting in a considerable improvement angiographically but continued filling of the lesion from the vertebral artery branches. The patient reported a marked improvement in his gait and balance; however the risk of symptom recurrence or future hemorrhage was felt to be high. Consequently, surgery was performed 2 weeks later. The venous outflow was exposed and clipped. The post-operative angiogram demonstrated complete thrombosis of the lesion (Figure 6) and the patient subsequently made a complete clinical recovery.

\section{3) Patient AL}

This 66-year-old male presented with a right cerebellar hemorrhage (Figure 7). He made a good clinical recovery apart from persistent ataxia. Cerebral angiography revealed a DAVF of the left petrous ridge, supplied primarily by meningohypophyseal branches of the left internal carotid artery (Figure 8). The straight sinus was occluded and there was PVD into the petrosal vein and into lateral mesencephalic and cerebellar hemispheric veins. The meningohypophyseal trunk was embolized with NBCA during temporary balloon occlusion of the internal carotid artery, but the DAVF continued to fill from meningeal branches of the left external and vertebral arteries. The patient was then taken to surgery and the large petrosal vein was identified (Figure 9A) and clipped (Figure 9B). The post-operative angiogram showed complete occlusion of the lesion (Figure 10). 

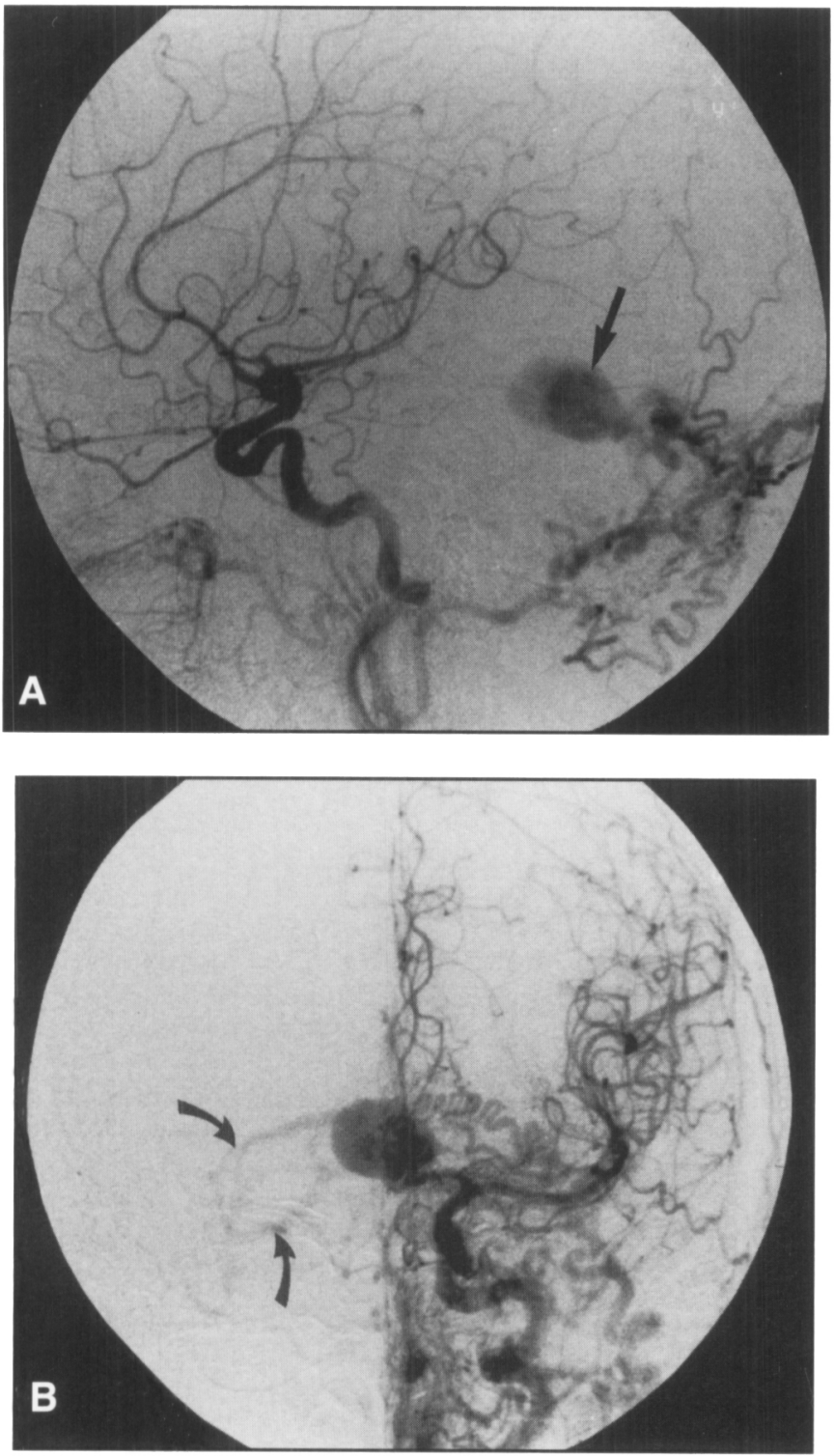

Figure 5: A left common carotid arteriogram, lateral $(\boldsymbol{A})$ and $A P(B)$ views shows a DAVF with $P V D$ into a large varix (large arrow) and pial cerebellar veins (curved arrows). The main arterial supply is from the occipital artery.

\section{4) Patient KF}

This 73-year-old male presented with episodes of slurred speech which were thought to represent left hemisphere transient ischemic attacks. On clinical examination, only mild sensory extinction of the left leg could be demonstrated. Carotid ultrasound had suggested a severe left internal carotid artery stenosis; however subsequent angiography showed the presence of a large DAVF of the superior sagittal sinus (Figure 11A, B). Arterial supply was from both middle meningeal arteries, both occipital arteries, the right superficial temporal artery and the right artery of the falx from the ophthalmic artery. Venous drainage was into the wall of the superior sagittal sinus and then into pial cerebral veins of the right hemisphere. Enlarged tortuous cortical veins drained into the right Sylvian region where multiple enlarged pial venous structures were identified. Embolization was undertaken to prevent future hemorrhage. During the first session, the right occipital artery was embolized with PVA particles. The right middle meningeal artery could not be catheterized due to a tortuous origin. During a second session, the left middle meningeal artery was embolized with PVA and NBCA and the left occipital artery was occluded with PVA parti-
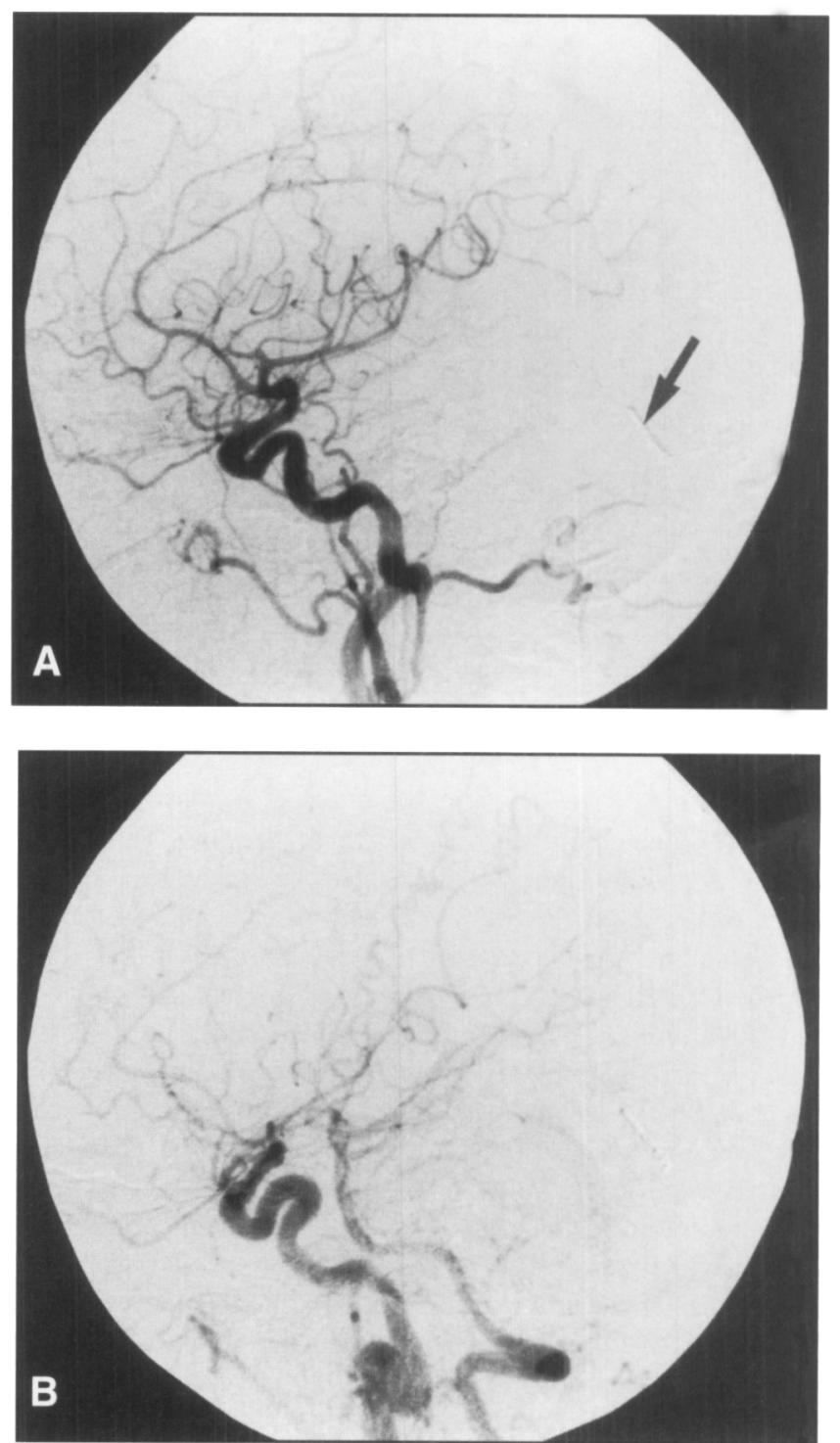

Figure 6: The post-operative left common carotid $(\boldsymbol{A})$ and innominate arteriograms (B) (lateral views) show complete thrombosis of the lesion. Note the surgical clip (arrow) which occludes the largest pial vein draining the varix.

cles. The post-embolization angiogram showed continued filling of the malformation from the right middle meningeal artery but much slower filling of draining veins in the right cerebral hemisphere. Due to the continued filling of the lesion and the risk of future hemorrhage, surgical therapy was performed 1 week later. The abnormal pial cerebral veins were isolated and clipped (Figure 12). The patient tolerated the procedure well and the post-operative angiogram showed complete obliteration of the malformation with preservation of the superior sagittal sinus (Figure 13).

\section{Discussion}

It is now generally believed that DAVFs are acquired lesions, usually related to prior partial or complete thrombosis in the adjacent venous sinus. ${ }^{4-6}$ This may be spontaneous or related to prior trauma or surgery. It is believed that this primarily thrombotic process leads to the opening of arterial and venous microcollaterals and the resultant AV fistula. The clinical course is 


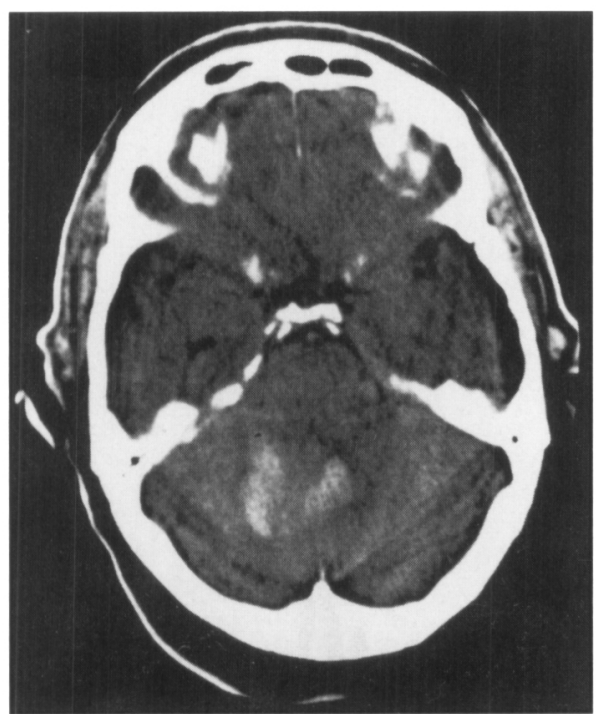

Figure 7: Non-contrast CT head scan shows a midline and right cerebellar hemorrhage.

most often dependent on the pattern of venous drainage and therapy is usually directed toward the venous component. ${ }^{1,4,5}$ Several classifications of these lesions have been proposed based on angio-architecture and clinical course. ${ }^{4.5}$ In the system proposed by Borden et al., ${ }^{5}$ Type I lesions consist of one or more fistulae between a meningeal artery and a dural venous sinus or dural meningeal vein. All blood flow in the veins is antegrade. These lesions usually present with pulsatile tinnitus, bruit or cranial nerve deficit, depending on location. The clinical course is usually benign. Type II lesions consist of 1 or more fistulae draining into a dural sinus and also into pial subarachnoid veins in which blood flow is therefore reversed. These patients present with symptoms due to venous hypertension or hemorrhage. Type III lesions drain into subarachnoid veins located at or in the wall of dural sinuses. They therefore drain retrogradely into a vein that normally drains into the sinus, which itself may be patent or occluded. If the sinus is patent, it is usually not in direct communication with the fistula and is isolated from the remaining dural venous structures. They also are more aggressive lesions, presenting with hemorrhage or other manifestations of venous hypertension. There are several subclassifications within this group, but they are all distinguished by the presence of drainage into subarachnoid veins. Another classification system has been proposed by Cognard et al., ${ }^{4}$ in which the Type I and II DAVFs are essentially identical in each system. In Cognard's system, Type III lesions demonstrate cortical venous drainage without venous ectasia, Type IV lesions do show venous ectasia and Type $\mathrm{V}$ lesions drain into spinal veins, similar to Borden's Type III. In both classifications, Type I lesions are relatively benign, whereas all the other groups have the potential for a more aggressive course.

Lasjaunias et al. ${ }^{19}$ reviewed 191 cases of DAVFs reported in the literature and included 4 cases of their own, in one of the first attempts to identify angiographic features predisposing to an aggressive clinical course. They concluded that focal neurological symptoms, including hemorrhage, were related to the presence of cortical venous drainage. The site of the lesion was not a significant determinant, but there was a trend for lesions
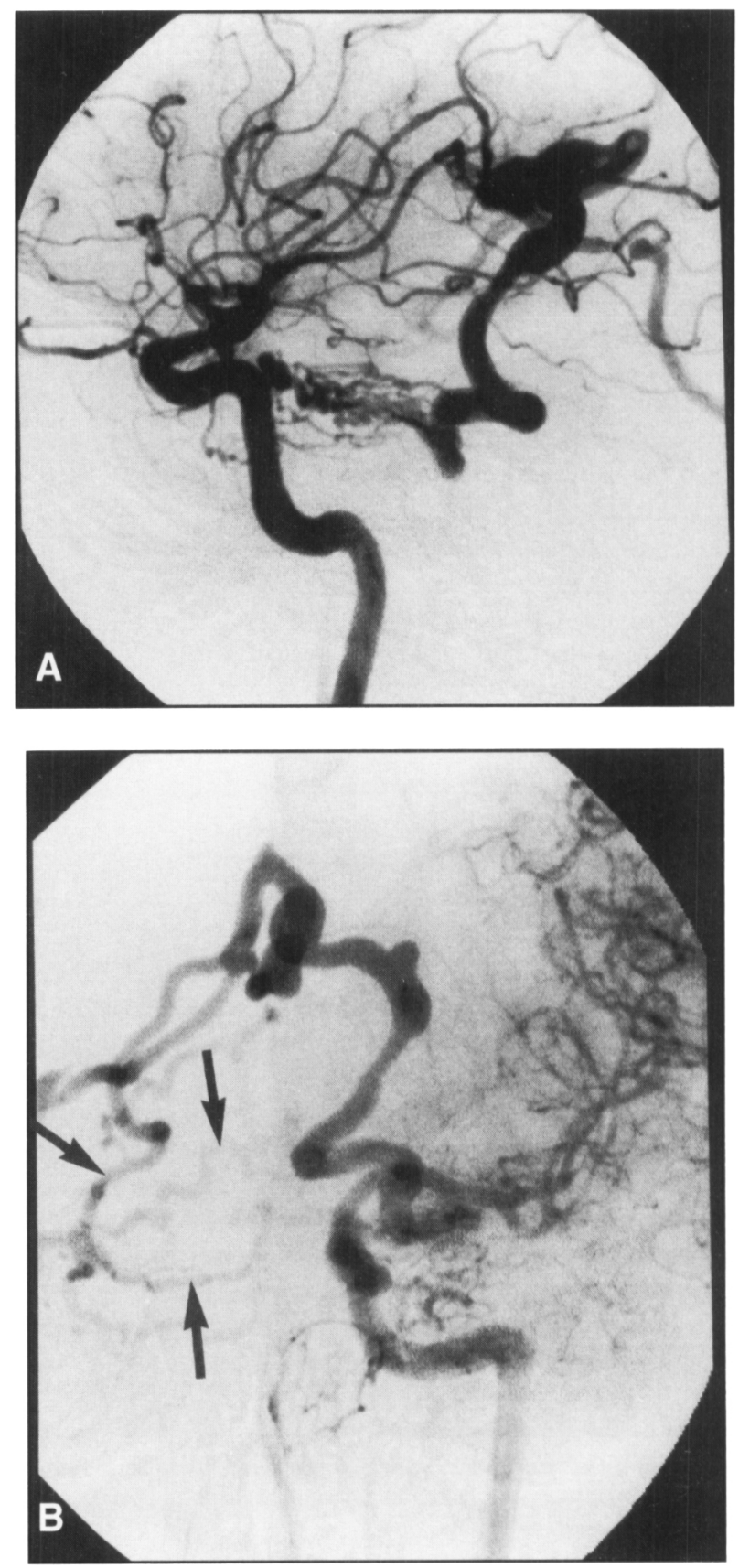

Figure 8: Left internal carotid arteriograms, lateral $(A)$ and $A P(B)$ views. There is a DAVF of the left petrous ridge, supplied primarily by meningohypophyseal branches of the left internal carotid artery. The straight sinus was occluded and there was PVD into the petrosal vein which drained into lateral mesencephalic and right cerebellar hemispheric veins (arrows).

near the tentorial incisura and in the floor of the anterior cranial fossa to behave in a more aggressive manner. These findings were confirmed by Awad et al..$^{20}$ who performed a meta-analysis of 360 cases of DAVF from the literature and included 17 cases of their own. The major factors determining aggressivity in their series were leptomeningeal venous drainage, variceal or aneurysmal venous dilatations, and Galenic drainage.

Treatment of Type I DAVFs is usually elective and related to alleviation of an intractable bruit. The treatment is usually 
A
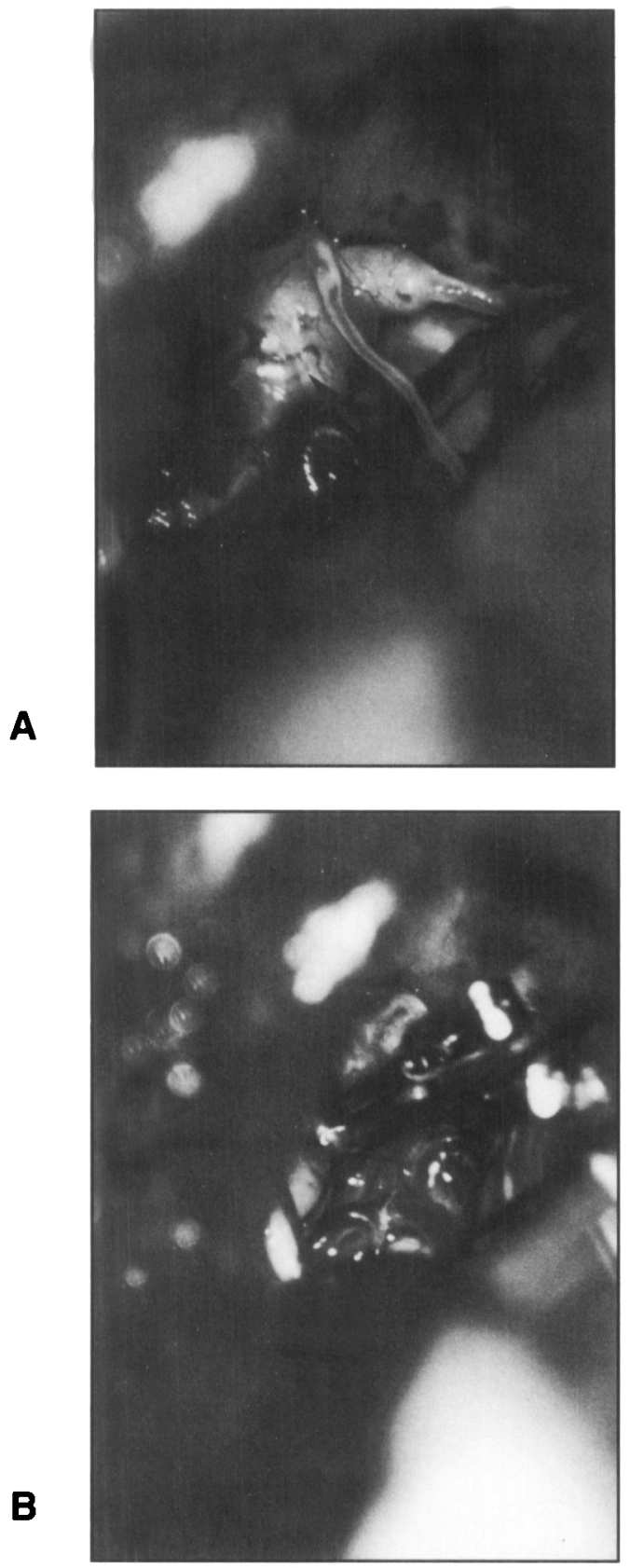

Figure 9: The large petrosal vein was identified $(A$, arrow) and clipped (B)

directed towards the arterial input, with embolization of arterial feeders resulting in complete cure up to $50 \%$ of patients. ${ }^{2,5.8}$ If the malformation drains into a sinus which may be sacrified (i.e., the sinus does not drain normal brain parenchyma) transvenous embolization with thrombogenic coils and liquid adhesive glues may increase the symptomatic cure rate. ${ }^{11-13}$ If the sinus must be preserved, then complete cure may be difficult. Surgical isolation (skeletonization) of the sinus may be considered in these cases, but it is a major surgical undertaking with relatively low success rates and up to a $15 \%$ risk of major morbidity or mortality. ${ }^{14}$

Treatment of Type II and higher lesions of the brain may be problematic, due to the complexity of arterial supply and variable accessibility of the venous drainage for interventional ther-

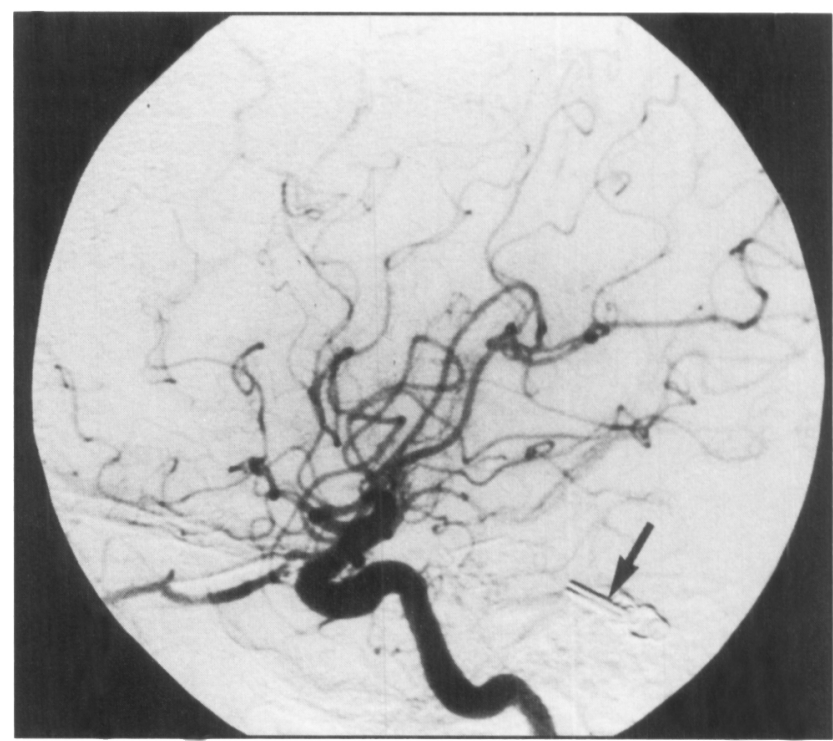

Figure 10: The post-embolization left common carotid arteriogram (lateral view) shows complete occlusion of the lesion. Note the surgical clips (arrow).

apy. Endovascular approaches have included transarterial ${ }^{2,7,8}$ and transvenous routes, $7,8,11-13$ including retrograde transvenous embolization following surgical exposure of the superior ophthalmic vein for cavernous DAVFs. ${ }^{15}$ Surgical approaches in the past have again focussed on interruption of arterial input and isolation of the venous sinus or draining veins. ${ }^{14}$ Radiation therapy may be useful for small lesions less than $25 \mathrm{~mm}$ in total diameter, but is less successful with larger lesions (Steiner $L$ and Drake CG, personal communication, 1992). Radiation therapy has been used with some success following transarterial embolization of tentorial DAVFs. ${ }^{16}$

Barnwell et al. ${ }^{17}$ have described their experience with combined endovascular - neurosurgical therapy in a series of 16 patients with complex DAVFs. In their series, embolization had been unsuccessful in curing these lesions and subsequent surgery was used to either provide access to arteries for further embolization, to isolate dural sinuses for direct embolization, or to completely resect the malformations. At least 4 of the illustrated cases clearly showed PVD, but no mention was made of ligation of these vessels as a definitive therapy. Venous ligations in this series were performed prior to direct injections of liquid acrylic agents for sinus obliteration and 1 of the complications resulted from glue migration into a pial mesencephalic vein. The other complication was a venous infarct following extensive surgical resection of a transverse - sigmoid sinus lesion.

It has been shown that DAVFs of the spine can be effectively treated by simple ligation of the arterialized pial veins which drain into the subarachnoid space. ${ }^{18}$ Thompson et al. ${ }^{9}$ attempted to determine whether a similar observation could be made with cranial DAVFs in which PVD was identified. They described the treatment of 4 patients with such lesions. Two patients had petro-tentorial DAVFs, 1 located in the floor of the middle cranial fossa and 1 in the posterior fossa. Venous drainage was entirely leptomeningeal into the petrosal vein, cerebellar and mesencephalic veins. Two of the patients were treated by simple surgical ligation of arterialized petrosal and cerebellar veins. In 

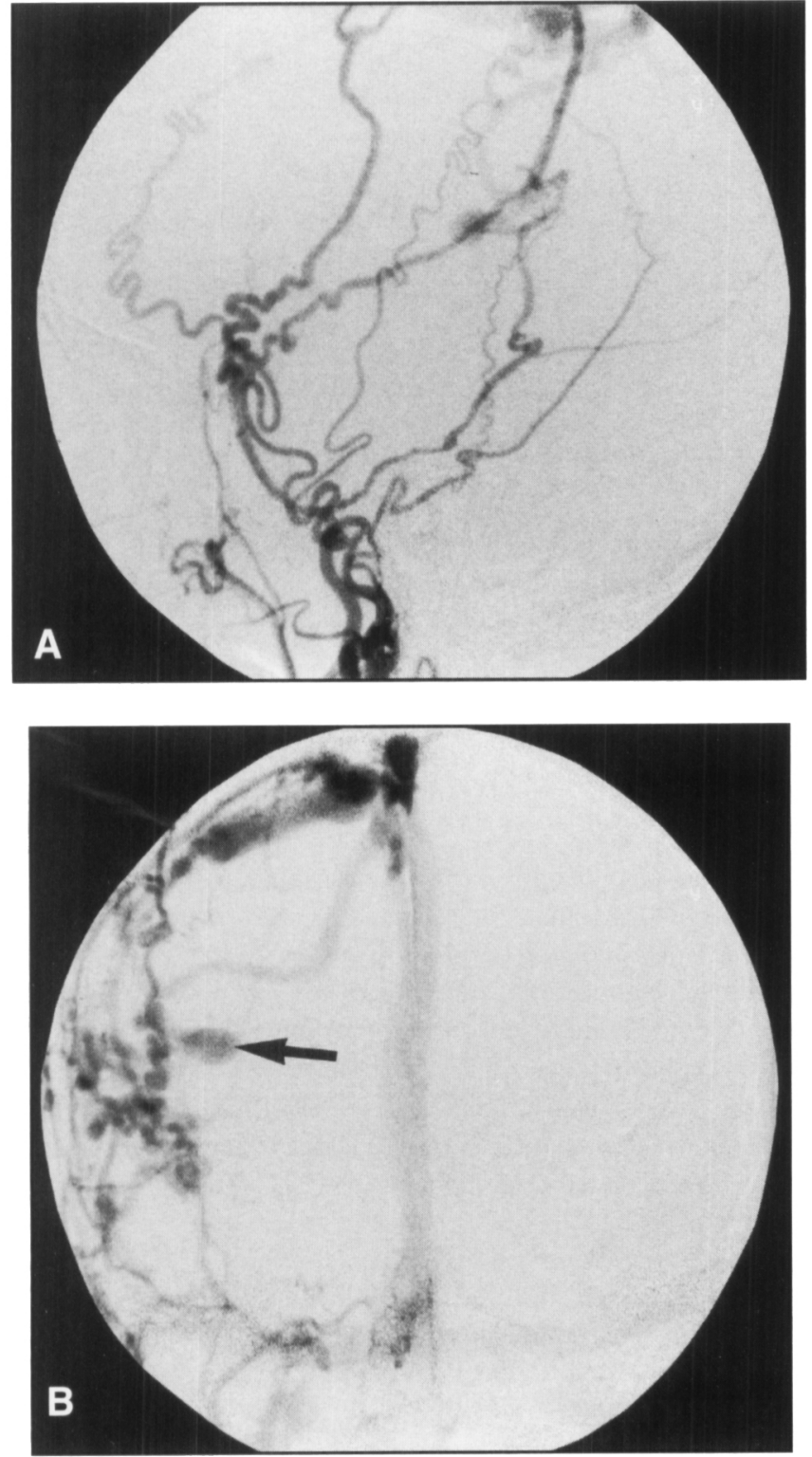

Figure 11: Lateral $(\boldsymbol{A})$ and $A P(B)$ views from a left external carotid arteriogram show a DAVF of the superior sagittal sinus, which was supplied by both external carotid arteries. There was pial venous drainage into right cerebral cortical veins (arrow).

the other 2 patients, ligation of the pial veins was preceded by incomplete transarterial embolization with PVA particles. There was complete angiographic occlusion of the fistulae in all patients with an excellent clinical outcome in 3 . The authors concluded that this subgroup of patients can be cured by simple interruption of the PVD without lengthy and potentially dangerous resection of the DAVF itself or the dural venous sinus. This theory was reinforced by Mullan ${ }^{6}$ who again noted the similarity to spinal lesions and the frequent inadequacy of transarterial embolization.

The results of our series would support the findings of Thompson et al. When endovascular therapy is unsuccessful in completely occluding the lesion, surgical interruption of the PVD may be a more direct and in some cases, less dangerous alternative. In our experience, endovascular therapy alone was
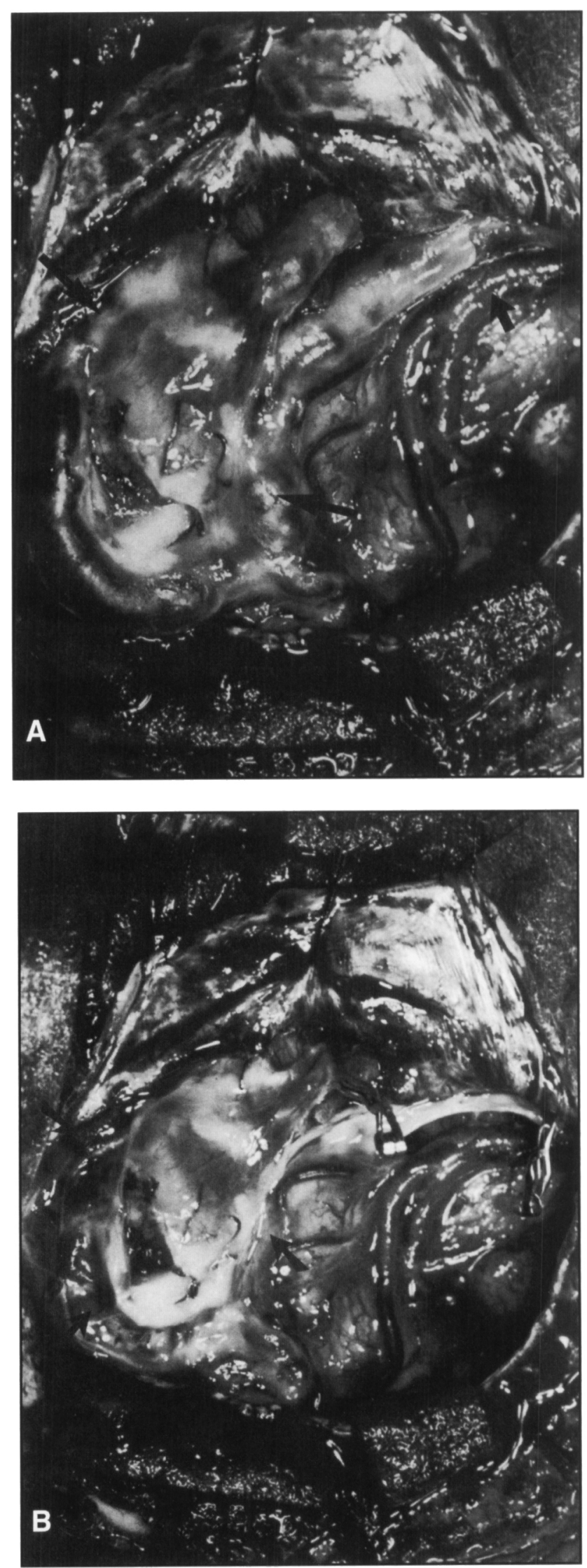

Figure 12: The pial venous drainage was identified ( $A$, large arrows). Note the normal cortical vein in comparison (small arrow). The largest veins were clipped, aspirated and collapsed (B, arrows). 

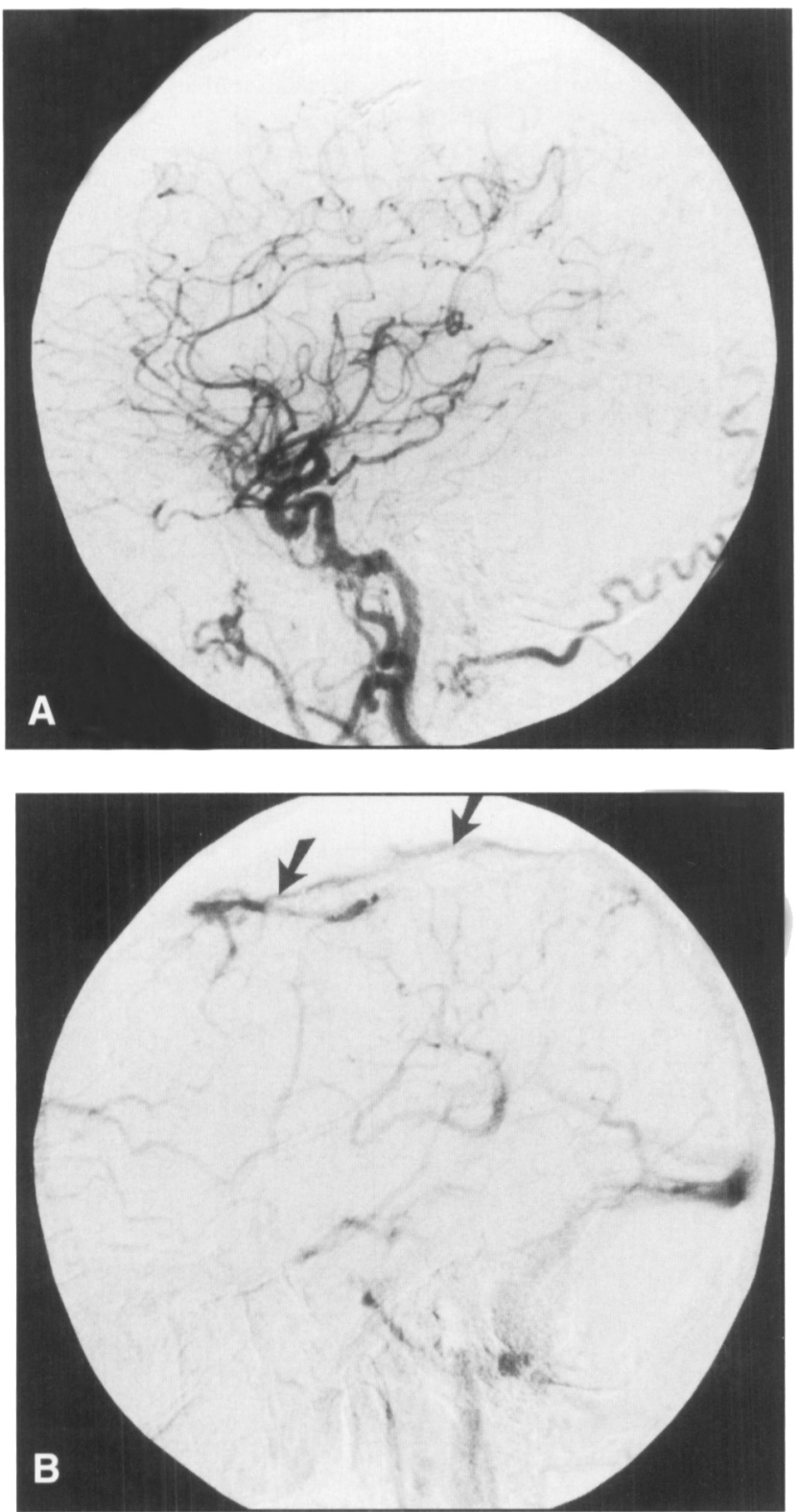

Figure 13: The post-operative right common carotid arteriogram, lateral views $(\boldsymbol{A} \& \boldsymbol{B})$ shows complete occlusion of the fistula with continued patency of the sinus (B, arrow).

curative in 4 of 6 patients, but both complications occurred following embolization. In 1 patient (CP) a subarachnoid hemorrhage occurred following glue injection into an arterial feeder, and in another patient (DJ), a seventh cranial nerve palsy resulted from an injection of glue into a middle meningeal artery branch. In the 4 patients treated with combined endovascular and surgical therapy, and in the 3 treated with surgery alone, complete cures were obtained in all with no complications arising from the surgery.

Endovascular therapy is appealing for the initial treatment of these lesions, as the vascular structures are frequently accessible and there is the opportunity to avoid what is often considered to represent major intracranial surgery. The treatment philosophy has often been to embolize first with the goal of eliminating as much of the arterial input and pial venous outflow as possible.
This is a reasonable approach when arterial and venous access routes are straightforward. Interventional therapy, however, carries definite risks, primarily those of hemorrhage, stroke and cranial nerve deficit and these risks may increase as access becomes more difficult and smaller vascular spaces are navigated and occluded. In this context, when the risks of endovascular therapy are becoming greater, it is worth considering the surgical alternative. This is particularly relevant when the PVD is clearly apparent and can be easily accessed surgically. Ligation of these veins is often curative and we have shown that in some cases, it should be performed as the primary therapy with no preliminary embolization. Incomplete embolization may reduce the magnitude of arteriovenous shunting and may reduce clinical symptomatology in benign varieties of DAVF. There is however no evidence that partial embolization with persistance of the PVD in aggressive lesions results in any reduction of stroke or hemorrhage risk for the patient.

In conclusion, DAVFs with PVD are aggressive lesions which demand urgent treatment due to the risk of hemorrhage or stroke. Endovascular therapy may be curative but is often complex and carries appreciable risks. A combined endovascular neurosurgical approach, in which direct interruption of the PVD may be sufficient for cure, should be considered when embolization alone (transarterial \pm transvenous) is unsuccessful or is unlikely to result in complete cure.

\section{REFERENCES}

1. Houser OW, Baker HL, Rhoton AL, Okazaki H. Intracranial dural arteriovenous malformations. Radiology 1972; 105: 55-64.

2. Vinuela F, Fox AJ, Pelz DM, Drake CG. Unusual clinical manifestations of dural arteriovenous malformations. J Neurosurg 1986; 64: 554-558.

3. Brown RD, Wieber DO, Nichols DA. Intracranial dural arteriovenous fistulae: angiographic predictors of intrancranial hemorrhage and clinical outcome in non-surgical patients. J Neurosurg 1994; 81: 531-538.

4. Cognard C, Gobin YP, Pierot L, et al. Cerebral dural arteriovenous fistulas: clinical and angiographic correlation with a revised classification of venous drainage. Radiology 1995; 194: 671-680.

5. Borden JA, Wu JK, Shucart WA. A proposed classification for spinal and cranial dural arteriovenous fistulous malformations and implications for treatment. J Neurosurg 1995; 82: 166-179.

6. Mullan S. Reflections upon the nature and management of intracranial and intraspinal vascular malformations and fistulae. J Neurosurg 1994; 80: 606-616.

7. Lownie SP. Intracranial dural arteriovenous fistulas: endovascular therapy. Neurosurg Clin North Am 1994; 5: 449-458.

8. Halbach VV, Hieshema GB, Higashida RT, Dowd CF. Endovascular therapy of dural fistulas. In: Vinuela F, Halbach VV, Dion JE, eds. Interventional Neuroradiology: Endovascular Therapy of the Central Nervous System. New York: Raven, 1992: 29-50.

9. Thompson BG, Doppman JL, Oldfield EH. Treatment of cranial dural arteriovenous fistulae by interruption of leptomeningeal venous drainage. J Neurosurg 1994; 80: 617-623.

10. Grisoli F, Vincentelli F, Fuch S, et al. Surgical treatment of tentorial arteriovenous malformations draining into the subarachnoid space. Report of 4 cases. J Neurosurg 1984; 60: 1059-1066.

11. Urtasun F, Biondi A, Casasco A, et al. Cerebral dural arteriovenous fistulas: percutaneous transvenous embolization. Radiology 1996; 199: 209-217.

12. Halbach V, Higishida RT, Hieshema GB, Mehringer CM, Hardin CW. Transvenous embolization of dural fistulas involving the transverse and sigmoid sinuses. Am J Neuroradiol 1989; 10: 385-392. 
13. Halbach VV, Higashida RT, Hieshema GB, Hardin CW, Pribram H. Tranvenous embolization of dural fistulas involving the cavernous sinus. Am J Neuroradiol 1989; 10: 377-382.

14. Sundt TM, Piepgras DG. The surgical approach to arteriovenous malformations of the lateral and sigmoid dural sinuses. $J$ Neurosurg 1983; 59: 32-39.

15. Monsein LH, Debrun GM, Miller NR, Nauta HJ, Chazaly JR. Treatment of dural carotid cavernous fistulas via the superior ophthalmic vein. Am J Neuroradiol 1991; 12: 435-439.

16. Lewis AI, Thomsick TA, Tew JM. Management of tentorial dural arteriovenous malformations: transarterial embolization combined with stereotactic radiation or surgery. J Neurosurg 1994; 81: 851-859.
17. Barnwell SL, Halbach VV, Higashida RT, Hieshema GB, Wilson CB. Complex dural arteriovenous fistulas. Results of combined endovascular and neurosurgical treatment in 16 patients. J Neurosurg 1989; 71: 352-358.

18. Oldfield EH, DiChiro G, Quindlen EA, et al. Successful treatment of a group of spinal cord arteriovenous malformations by interruption of dural fistula. J Neurosurg 1983; 59: 10191030.

19. Lasjaunias $\mathrm{P}$, Chiu M, Ter Brugge $\mathrm{K}$, et al. Neurologic manifestations of intracranial dural arteriovenous malformations. $J$ Neurosurg 1986; 64: 724-730.

20. Awad IA, Little JR, Akrawi WP, Ahl J. Intracranial dural arteriovenous malformations: factors pre-disposing to an aggressive neurological course. J Neurosurg 1990; 72: 839-850. 